\title{
Internal exposure levels of polycyclic aromatic hydrocarbons in children and adolescents: a systematic review and meta- analysis
}

\author{
Xin Huang, Xu Deng, Wenyan Li, Shudan Liu, Yiwen Chen, Bo Yang and Qin Liu*
}

\begin{abstract}
Polycyclic aromatic hydrocarbons (PAHs) are widely found in the environment, and comparing to adults, children are more vulnerable to PAHs exposure. Urinary metabolites of PAHs are used as preferred biomarkers to estimate the PAHs exposure. Systematic review on the internal exposure level of children and adolescents is rare. We aimed to calculate the internal exposure levels of PAHs in children and adolescents and compare the levels of PAHs internal exposure in various children groups. We searched PubMed, OVID, Web of Science, EBSCO, ACS, and four Chinese databases, and all studies examining the urinary concentrations of PAHs in children and adolescent were identified. The total exposure level of 11 PAHs metabolites were pooled. Standard mean difference (SMD) and 95\% confidence intervals (Cls) of PAHs urinary concentration were calculated and pooled by RevMan5.3 to compare the exposure levels of different children groups. We found that 1-OHPyr, 2-OHNap, 2-OHFlu, 3-OHPhe, and 4-OHPhe were five PAHs metabolites most commonly studied in existing studies in children, and their total exposure levels were $0.38 \pm 0.98,2.32 \pm 4.83,0.81 \pm 1.54,0.09 \pm 0.14,0.03 \pm$ $0.10 \mu \mathrm{mol} / \mathrm{mol}$ creatinine, respectively. The meta-analysis showed that the levels of 1-OHPyr were higher in higher environmental exposure group ( $\mathrm{SMD}=0.21,95 \% \mathrm{Cl}=0.03 \sim 0.40$ ), ETS exposure group ( $\mathrm{SMD}=0.31,95 \% \mathrm{Cl}=0.08 \sim 0.54$ ), and $6 \sim 11$ years group $(\mathrm{SMD}=0.16,95 \% \mathrm{Cl}=0.09 \sim 0.24)$; the level of $2-\mathrm{OHNap}(\mathrm{SMD}=0.27,95 \% \mathrm{Cl}=0.01 \sim 0.53)$ was higher in higher environmental exposure group; however, the levels of 3-OHPhe (SMD $=-0.34,95 \% \mathrm{Cl}=-0.57 \sim-0.12)$ and 4-OHPhe (SMD $=-0.48,95 \% \mathrm{Cl}=-0.69 \sim-0.28)$ were higher in lower environmental exposure group. The levels of 1-OHPyr (SMD $=-0.01,95 \% \mathrm{Cl}=-0.11 \sim 0.10)$ and 2-OHNap $(\mathrm{SMD}=0.01,95 \% \mathrm{Cl}=-0.20 \sim 0.22)$ were not statistically different between boys and girls. In conclusions, we found that the internal diversity of PAHs existed in children and adolescents, and the level of 1-OHPyr in children and adolescents was in higher status compared with non-occupational people who do not smoke.
\end{abstract}

Keywords: Polycyclic aromatic hydrocarbons, Children, Biological markers, Systematic review, Meta-analysis

\section{Introduction}

Polycyclic aromatic hydrocarbons (PAHs) are a group of over 100 different organic pollutants, which are widely found in the environment [1]. The major sources of PAHs are formed during the incomplete burning of coal, oil and gas, garbage, or other organic substances like tobacco or charbroiled meat [2]. Due to the numerous

\footnotetext{
* Correspondence: liuqin81622@163.com

School of Public Health and Management, Research Center for Medicine and Social Development, Collaborative Innovation Center of Social Risks Governance in Health, Chongqing Medical University, No. 1 Yixueyuan Road Yuzhong District, Chongqing 400016, China
}

PAHs exposure sources, humans can be exposed to PAHs through multiple routes, including breathing polluted air, environmental tobacco smoke (ETS), dietary PAHs intake, and dermal absorption through soil, air, or particulate deposited on skin [3-5].

The exposure of PAHs in human has raised public health concerns. The United States Environmental Protection Agency (USEPA) has designated $16 \mathrm{PAH}$ compounds as priority pollutants $[3,6]$. Among PAHs, benzo[a]pyrene $(\mathrm{BaP})$ has been classified as a probable human and animal carcinogen by the International Agency for Research on Cancer (IARC) [7, 8]. The exposure of PAHs has been

(c) The Author(s). 2019 Open Access This article is distributed under the terms of the Creative Commons Attribution 4.0 International License (http://creativecommons.org/licenses/by/4.0/), which permits unrestricted use, distribution, and reproduction in any medium, provided you give appropriate credit to the original author(s) and the source, provide a link to the Creative Commons license, and indicate if changes were made. The Creative Commons Public Domain Dedication waiver (http://creativecommons.org/publicdomain/zero/1.0/) applies to the data made available in this article, unless otherwise stated. 
linked to the onset of diabetes mellitus [9], metabolic syndrome [10], and cardiovascular conditions [11]. Several studies reported that genotoxicity [12], oxidative stress [13], asthma [14], and neurodevelopment [15] were related to the exposure of PAHs. Besides, it has been found that PAHs exposure may be association with Cytochrome P450s (CYPs) induction and bioactivation, thereby leading to carcinogenesis [16]. Furthermore, existing studies showed that children are more vulnerable to PAHs exposure. Huang et al. reported that urinary 1-hydroxypyrene (1-OHPyr) concentration in children (6-11 years old) was approximately $30 \%$ higher compared to that in adults under the same conditions, indicating that children seem more susceptible to PAHs and have higher potential health risks [50].

Compared to monitoring of the external environment (e.g., measurement of chemicals in air, water, or soil), human biomonitoring reflects internal exposure in the human through different routes of exposure [17]. After entering the human body and biotransformation, PAHs are excreted in the form of hydroxylated metabolites in the urine or stool [18]. Biomarkers can provide an integrated reflection for exposure through inhalation, food and dermal uptake, and takes into account variation in absorption, metabolism, and elimination by the body. Therefore, the urinary metabolites of these compounds are used as preferred biomarkers to estimate the PAHs exposure [19].

To date, a number of studies have detected the urinary metabolites concentration of PAHs; however, the biomarkers and characteristics were diverse. Several studies conducted a review on the concentration of urinary metabolites and biomarkers of PAHs. A comprehensive review on occupational exposure to PAHs by Bouchard et al. [20] revealed that urinary 1-OHPyr increased in course of a working day. Hansen et al. [21] reviewed 132 studies addressing the use of 1-OHPyr as a biomarker of both occupational and environmental exposure to PAH. Of these, 25 studies addressed environmental exposure, and only nine included children. The existing reviews on PAHs metabolites concentration are focused more on adults, but comprehensive review on the internal exposure level of children and adolescence is rare. The purpose of this study was to estimate the total non-occupational internal exposure level in children using different hydroxylated metabolites and to compare the levels of PAHs internal exposure in various children groups. Furthermore, a reference for future research and evaluation on PAHs biomarkers in children will be provided from the estimated total internal exposure level.

\section{Methods}

\section{Selection criteria}

The inclusion criteria included (1) studies that reported the urinary concentrations of PAHs metabolites; (2) participants: children and adolescents whose age under 20 years; and (3) outcome: concentration of PAHs hydroxylated metabolites (the preferred indicators were mean and standard deviation, median and range were included after calculating by formula). We excluded studies if (1) the studies were reviews, editorials, meeting abstracts, or commentaries; and (2) the small sample size studies detected concentration of PAHs to verify the feasibility of detection method. We did not have language restrictions.

\section{Search strategy}

The databases including PubMed (1978 to January 2017), OVID (1946 to January 2017), Web of Science (1970 to January 2017), EBSCO (1976 to January 2017), ACS(1879 to January 2017), CNKI (1979 to January 2017), WANFANG DATA (1987 to January 2017), CBM (1978 to January 2017), and CQVIP (1989 to January 2017) were searched using both the MeSH terms and free terms "Polycyclic Aromatic Hydrocarbons" or "PAHs" or "hydroxypyrene" or "hydroxyfluorene" or "hydroxyphenanthrene" or "hydroxynaphalene" or "hydroxyfluoranthrene" or "hydroxybenzo[c]phenanthrene" or "hydroxychrysene" or "hydroxybenz[a]anthracene," in combination with "urinary." We modified the search strategy when searching in different databases. No language restrictions or restrictions on publication type were applied. All the retrieved literatures were entered into reference-managing software (EndNote, version X6, Thomson Scientific, Stamford, CT, USA) for duplicate check.

\section{Data screening and extraction}

Two reviewers independently screened all the retrieved literature by titles and abstracts. The potential eligible studies were then screened again by full texts. The predesigned criteria mentioned above were used to guide the entire process of screening. Subsequently, the following data were extracted from all the included studies using a pre-designed extraction form by two reviewers: (1) general information, including authors, publication year, country; (2) study design and methodological quality; (3) participants characteristics and sample size; (4) sample collection season; (5) analyte detection and adjusted methods; and (6) outcome measures, including type of metabolites, outcome indicators, and concentrations of metabolites. Disagreements during screening and data extraction were resolved by discussion or consultation with the third reviewer to reach a consensus.

\section{Risk of bias assessment}

Two reviewers independently assessed the methodology quality of included studies using the checklist recommended by Agency for Healthcare Research and Quality (AHRQ) [22]. Every item should be answered by "Yes," 
"No," or "Unclear." Disagreements were resolved by discussion or consultation with the third reviewer to reach a consensus.

\section{Recalculation of urinary PAHs}

The given concentrations were recalculated where the concentrations were given in the unit of $\mathrm{ng} / \mathrm{g}$ creatinine, $\mathrm{ng} / \mathrm{mg}$ creatinine, and $\mathrm{nmol} / \mathrm{mol}$ creatinine. For the recalculation molecular weight of hydroxypyrene (218.25), hydroxynaphthalene (144.17), hydroxyfluorene (182.22), hydroxyphenanthrene (194.23), and creatinine (113.12) were used. Outcome reported with median and ranges or median and interquartile range were converted to means and standard deviations according to the formula for approximately estimating [23, 24].

\section{Statistical analysis}

A statistical formula (Fig. 1) was used to synthesize means and standard deviations to get a total level of PAHs metabolites. The standard mean difference (SMD) and $95 \%$ confidence interval $(95 \% \mathrm{CI})$ of concentrations of PAHs metabolites were used to conduct meta-analyses using the software of Review Manager Software (Version5.3, Cochrane Collaboration, London, UK) for comparison between different children groups. The statistical heterogeneity of the included studies was assessed by $X^{2}$ test and $I^{2}$ index. A random effects model was used when heterogeneity was found to be significant $\left(I^{2}>50 \%\right.$ or $\left.P<0.05\right)$; otherwise, the fixed effects model was used. Subgroup analysis was conducted according to different study period, countries, ages, sample collection seasons, and approximately estimating or not. Sensitivity analyses were conducted using the leave-one-out approach for all the outcomes. To examine the potential publication bias, we used the funnel plot firstly. When larger and smaller studies were non-symmetrically distributed, visual inspection of the funnel plot offered an indication of publication bias. The presence of publication bias was further tested using Begg's test and Egger's test by STATA 12.0 software (StataCorp LP, College Station, TX). A $P \leq 0.05$ was considered to be statistically significant.

\section{Results}

\section{Screening results}

The process of study selection is shown in Fig. 2 with an adapted PRISMA (Preferred reporting items for systematic reviews and meta-analyses) flow diagram [25]. A total of 4776 records were identified after searching the literature. After duplicate checking, 2984 studies were excluded after the initial screening of titles and abstracts. Forty studies described in 42 articles [26-67] involving 12697 subjects were included in the final review after a strict screening process based on eligibility criteria, of which, 26 studies $[26-53,66]$ were included in the meta-analysis. The other 315 studies were excluded because they did not report the concentration of PAHs, or were not relevant to children and adolescent, or duplicate publication or studies were reviews, meeting abstracts, or commentaries.

\section{Characteristics of included studies}

Table 1 presents the main characteristics of included studies. The earliest study began in 1993. Seventeen [27, $28,30-32,38,41-43,47,50,52,53,56,59,60,64,67]$ of 40 studies were performed in developed countries or regions, and $23[26,29,33-37,39,40,44-46,48,49,51$, $54,55,57,58,61-63,65,66]$ were conducted in developing countries. A total of 12697 children were enrolled in this review, of which age range were 0 20 years. Six studies $[39,46,48,61,63,64]$ did not mentioned the age of subjects, but they reported that the subjects were all the elementary school students. Six studies $[45,48,54$, $55,59,62$ ] detected the level of PAHs metabolites only in boys, the remaining [26-44, 46, 47, 49-53, 56-58, 60, 61, 63-67] included both girls and boys. Five out of 40 studies [30-32, 50, 52, 56] determined the PAHs metabolites by gas chromatography (GC), the remaining [26$29,33-49,51,53-55,57-67]$ used the high-performance liquid chromatography (HPLC) method. The numbers of metabolites were from one to 11 , and all the studies reported concentration of 1-OHPyr. Of the 42 articles based on the 40 studies, 29 [26, 28, 29, 32-34, 36, 38$44,46,48,49,53-64]$ reported the level of PAHs by mean and standard deviation, five [30, 31, 50-52] reported by mean and its $95 \% \mathrm{CI}$, three [27, 45, 67]

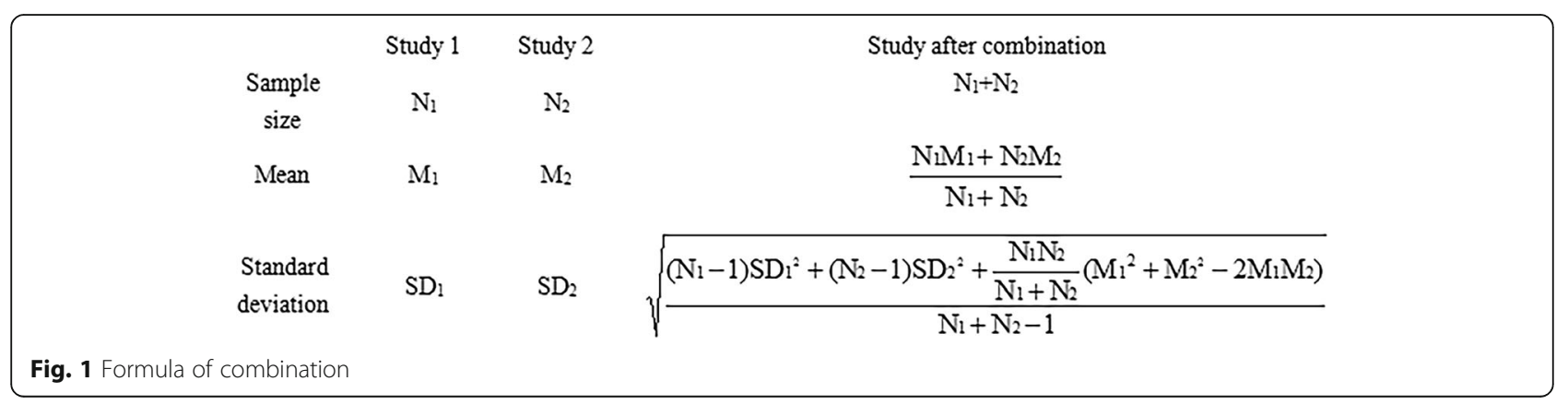




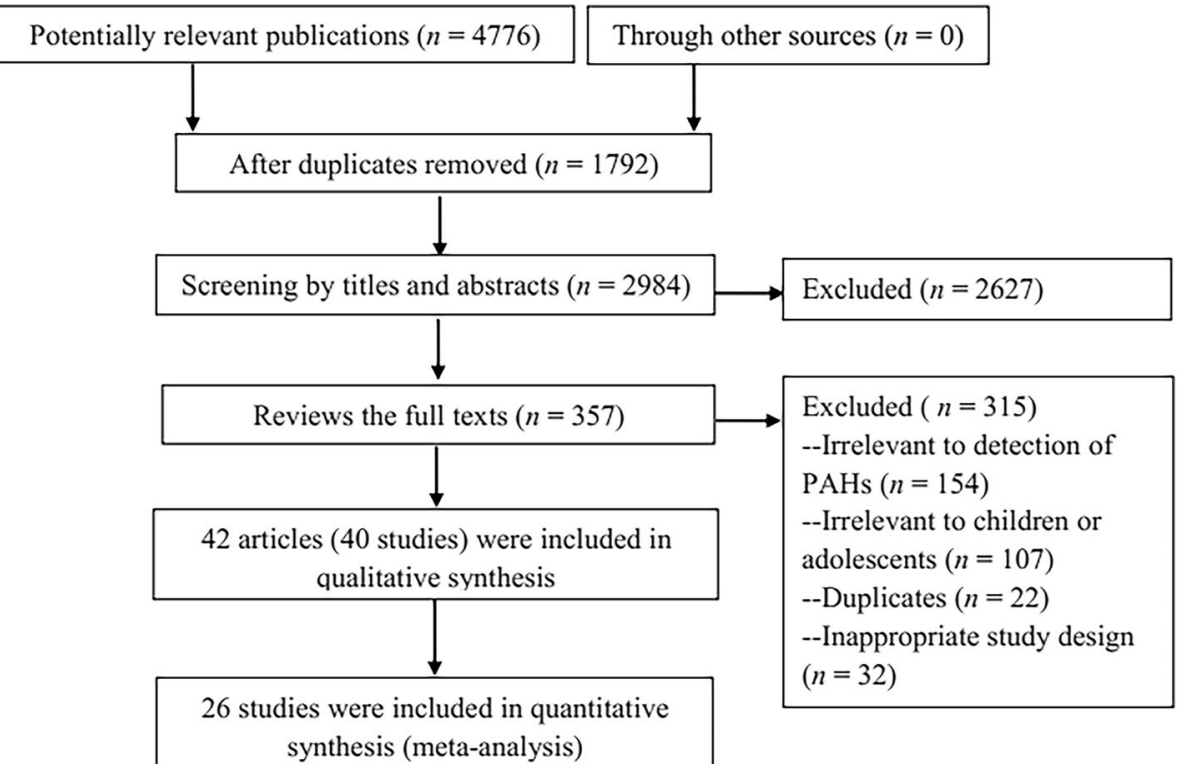

Fig. 2 Flow diagram of literature search

reported by mean and range, three $[47,65,66]$ reported by median and range, and two $[35,37]$ reported by median and interquartile range. Thirty-seven of 40 studies reported the PAHs metabolites concentrations adjusted by creatinine, one study in two papers $[30,31]$ reported the concentrations adjusted by urine specific gravity (SG), and two studies [51, 64] reported the unadjusted concentrations. Sixteen studies compared the urine PAHs metabolites levels between children living in higher PAHs exposure environment and lower exposure environment. The higher living environment included the urban areas $[27,32,38,41,45]$, industrial city or areas [40, 46, 48, 49], commercial areas [39], and schools or communities close to main roads [44], steel plant [43], steel mill and coking facility [33], power plant [42], coke oven plant [47], or oil refinery [37]. Oppositely, the rural areas [27, 32, 38, 41, 45, 47], tourist city [40], agricultural or residential areas [46, 48, 49], and schools or communities far away from the industry plants $[33,37$, 42-44] were regarded as the lower living environment.

\section{Risk of bias in included studies}

The quality assessment of cross-sectional studies was shown in Table 2. Of the 11 items in quality assessment, all the studies reported the data sources, inclusion and exclusion criteria for exposed and unexposed subjects, study period, and all the subjects were consecutive; it is unclear in all studies that whether or not the evaluators of subjective components were masked to other aspects of the status of the participants; only two studies [51, 64] did not adjust the levels of PAHs; five studies [30, 31, 33, 42, 43, 45] described the reasons for sample exclusions from analysis; 15 studies [34, 40, 44, $46-49,56-58,60,63,65-67]$ did not describe how to control confounding factors; only two studies $[43,45]$ explained how to deal with the data below the limit of detection; 11 studies [27, 33, 35-37, 42, 43, 45, 47, $50,51,60]$ described the completeness of data collection; and four studies [26, 30, 31, 43, 48] had followups and reported the percentage of patients obtained in follow-ups.

\section{Total exposure levels of PAHs}

In this study, the concentration of 11 PAHs metabolites in urine of children and adolescents were pooled based on the 37 studies [26-29, 32-50, 52-63, 65-67] reporting the concentrations adjusted by creatinine respectively. 1OHPyr, 2-OHNap, 2-OHFlu, 3-OHPhe, and 4-OHPhe were five PAHs metabolites most commonly used in existing studies, and their total exposure levels were $0.38 \pm$ $0.98, \quad 2.32 \pm 4.83, \quad 0.81 \pm 1.54, \quad 0.09 \pm 0.14$ and $0.03 \pm$ $0.10 \mu \mathrm{mol} / \mathrm{mol}$ creatinine, respectively. Among three age groups, the concentration of 9-OHPhe $(1.90 \pm 1.20)$ in children under six were higher than those in other age groups; the concentration of 1 -OHPyr $(0.45 \pm 0.75)$ in children aged 6 to 11 years was higher than that in other groups. Between the age groups of 6 to 11 years and 12 to 20 years, the concentration of 1-OHNap $(1.95 \pm 2.56)$, 2OHNap $(2.37 \pm 5.34)$, 3-OHFlu $(0.09 \pm 0.22)$, and 9-OHFlu $(0.15 \pm 0.36)$ in adolescent aged 12 to 20 years were higher than those in six to 11 years group; the concentration of 2 -OHFlu $(1.48 \pm 0.20), 1$-OHPhe $(0.09 \pm 0.17)$, 2 -OHPhe $(0.07 \pm 0.19), 3$-OHPhe $(0.14 \pm 0.20)$, and 4 OHPhe $(0.04 \pm 0.15)$ in children aged 6 to 11 years 


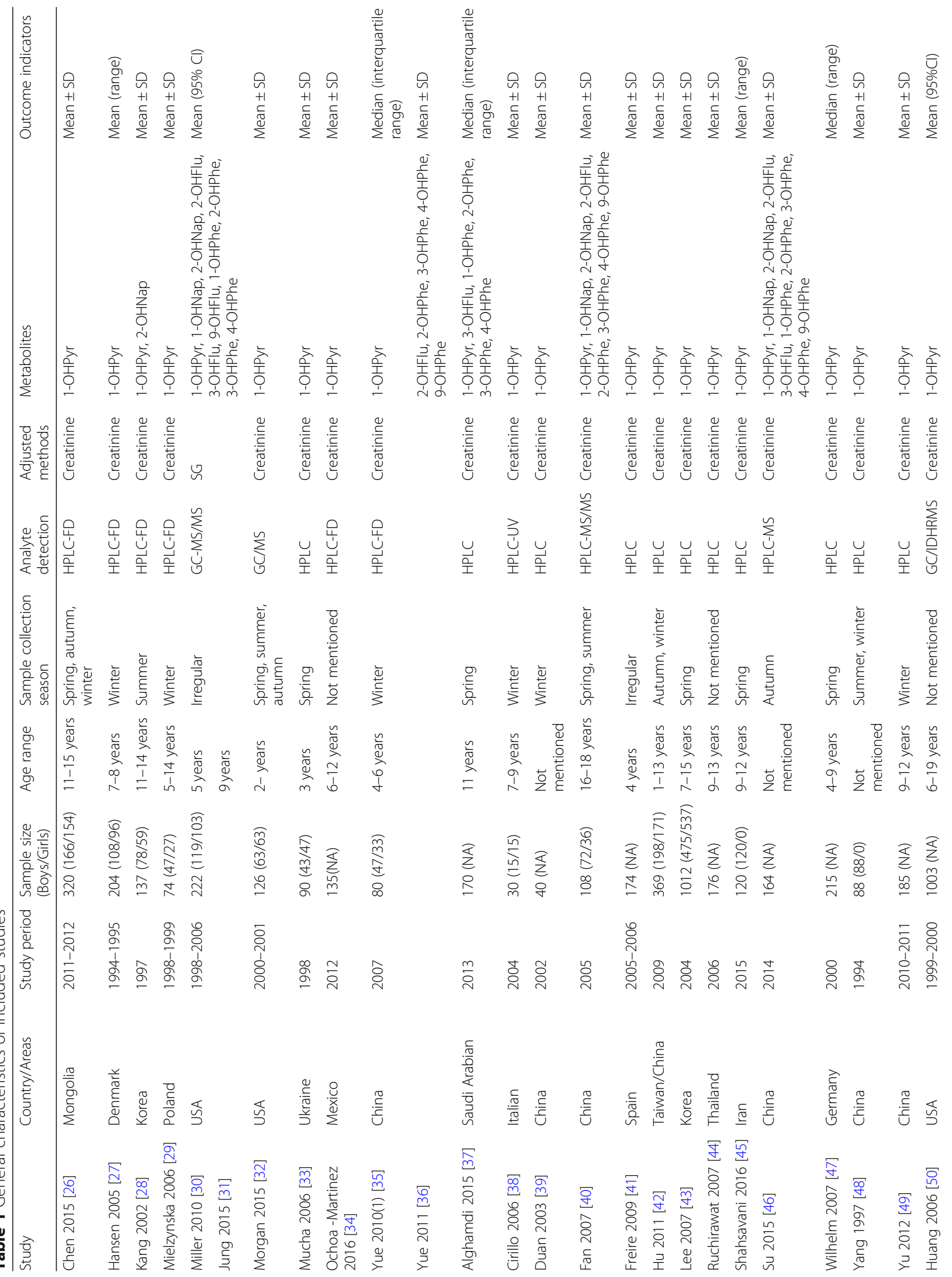




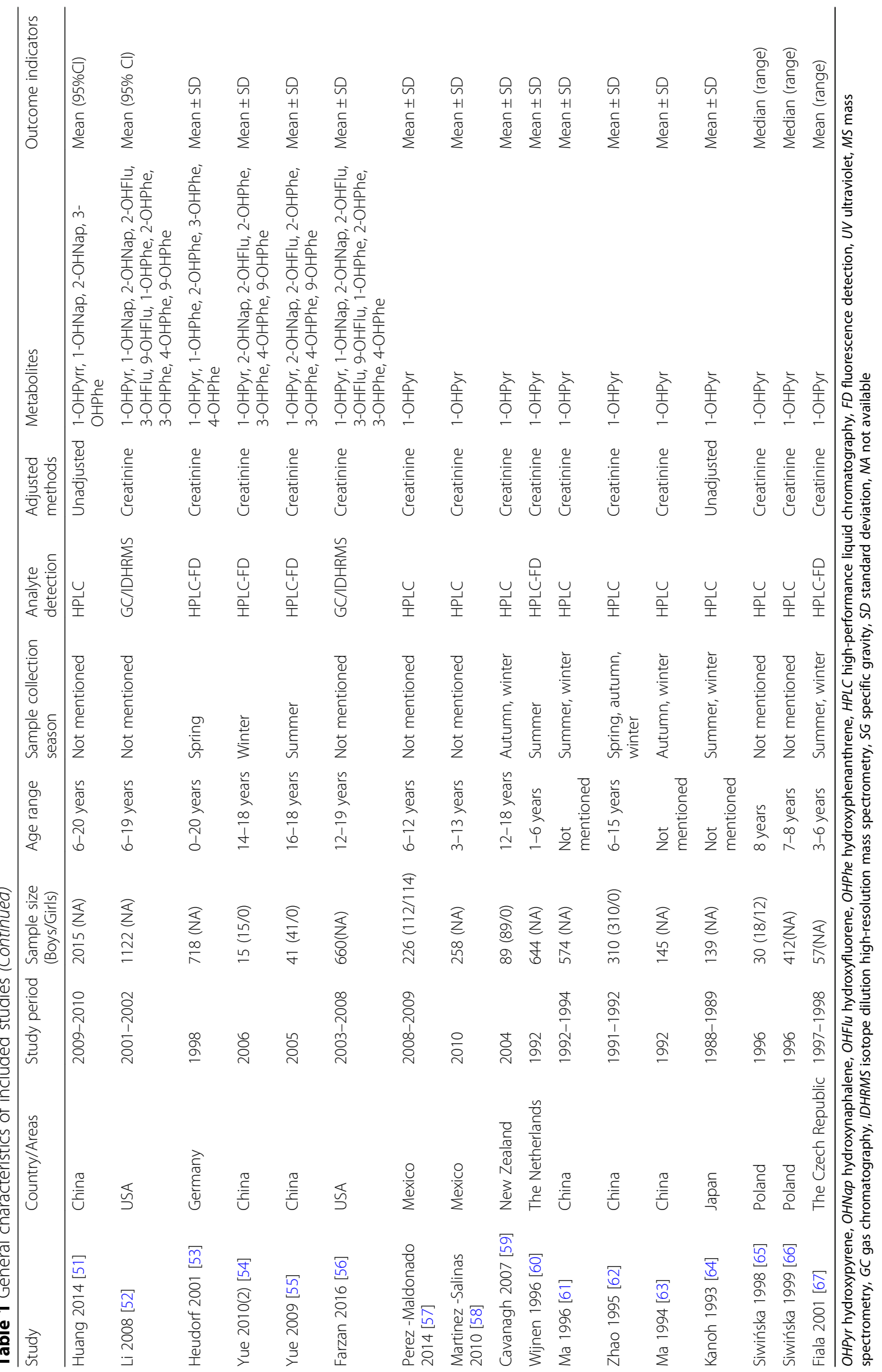


Table 2 AHRQ for assessing the methodology quality of included studies

\begin{tabular}{|c|c|c|c|c|c|c|c|c|c|c|c|}
\hline Study & (1) & (2) & (3) & (4) & (5) & (6) & (7) & (8) & (9) & (10) & (11) \\
\hline Chen 2015 [26] & Y & $\mathrm{Y}$ & Y & Y & $U$ & Y & $\mathrm{N}$ & $\mathrm{Y}$ & $\mathrm{N}$ & N & Y \\
\hline Hansen 2005 [27] & Y & Y & Y & Y & U & Y & $N$ & Y & $\mathrm{N}$ & Y & N \\
\hline Kang 2002 [28] & Y & Y & Y & Y & $u$ & Y & $N$ & Y & $\mathrm{N}$ & N & N \\
\hline Mielzynska 2006 [29] & Y & Y & Y & Y & $U$ & Y & $N$ & Y & $\mathrm{N}$ & N & N \\
\hline Miller 2010 [30] & Y & Y & Y & Y & U & Y & Y & Y & $N$ & Y & Y \\
\hline \multicolumn{12}{|l|}{ Jung 2015 [31] } \\
\hline Morgan 2015 [32] & Y & Y & Y & Y & U & Y & N & Y & $\mathrm{N}$ & N & N \\
\hline Mucha 2006 [33] & Y & Y & Y & Y & U & Y & Y & Y & $\mathrm{N}$ & Y & N \\
\hline Ochoa-Martinez 2016 [34] & Y & Y & Y & Y & U & Y & N & $\mathrm{N}$ & $\mathrm{N}$ & N & $\mathrm{N}$ \\
\hline Yue 2010(1) [35] & Y & Y & Y & Y & $u$ & Y & N & Y & N & Y & $\mathrm{N}$ \\
\hline \multicolumn{12}{|l|}{ Yue 2011 [36] } \\
\hline Alghamdi 2015 [37] & Y & Y & Y & Y & $u$ & Y & N & Y & $\mathrm{N}$ & N & N \\
\hline Cirillo 2006 [38] & Y & Y & Y & Y & $u$ & Y & N & Y & $\mathrm{N}$ & N & $\mathrm{N}$ \\
\hline Duan 2003 [39] & Y & Y & Y & Y & $u$ & Y & N & Y & $\mathrm{N}$ & N & N \\
\hline Fan 2007 [40] & Y & Y & Y & Y & u & Y & N & $\mathrm{N}$ & $\mathrm{N}$ & N & $\mathrm{N}$ \\
\hline Freire 2009 [41] & Y & Y & Y & Y & u & Y & N & Y & $\mathrm{N}$ & N & $\mathrm{N}$ \\
\hline Hu 2011 [42] & Y & Y & Y & Y & $u$ & Y & Y & Y & $\mathrm{N}$ & Y & $N$ \\
\hline Lee 2007 [43] & Y & Y & Y & Y & $u$ & Y & Y & Y & Y & Y & Y \\
\hline Ruchirawat 2007 [44] & Y & Y & Y & Y & u & Y & $N$ & $N$ & $\mathrm{~N}$ & N & N \\
\hline Shahsavani 2016 [45] & Y & Y & Y & Y & u & Y & Y & Y & Y & Y & N \\
\hline Su 2015 [46] & Y & Y & Y & Y & u & Y & N & N & $\mathrm{N}$ & N & $\mathrm{N}$ \\
\hline Wilhelm 2007 [47] & Y & Y & Y & Y & u & Y & N & $\mathrm{N}$ & $\mathrm{N}$ & Y & $\mathrm{N}$ \\
\hline Yang 1997 [48] & Y & Y & Y & Y & u & Y & N & $\mathrm{N}$ & $N$ & N & Y \\
\hline Yu 2012 [49] & Y & Y & Y & Y & u & Y & N & N & $N$ & N & $N$ \\
\hline Huang 2006 [50] & Y & Y & Y & Y & u & Y & N & Y & $\mathrm{N}$ & Y & $N$ \\
\hline Huang 2014 [51] & Y & Y & Y & Y & u & $\mathrm{N}$ & $N$ & Y & $N$ & Y & $N$ \\
\hline Li 2008 [52] & Y & Y & Y & Y & u & Y & N & Y & $N$ & N & $N$ \\
\hline Heudorf 2001 [53] & Y & Y & Y & Y & u & Y & N & Y & $\mathrm{N}$ & N & $N$ \\
\hline Yue 2010(2) [54] & Y & Y & Y & Y & u & Y & N & Y & $\mathrm{N}$ & N & $N$ \\
\hline Yue 2009 [55] & Y & Y & Y & Y & u & Y & N & Y & $\mathrm{N}$ & N & $N$ \\
\hline Farzan 2016 [56] & Y & Y & Y & Y & u & Y & N & $\mathrm{N}$ & $N$ & N & $N$ \\
\hline Perez-Maldonado 2014 [57] & Y & Y & Y & Y & U & Y & N & $\mathrm{N}$ & N & N & $\mathrm{N}$ \\
\hline Martinez-Salinas 2010 [58] & Y & Y & Y & Y & U & Y & N & $\mathrm{N}$ & $\mathrm{N}$ & N & $\mathrm{N}$ \\
\hline Cavanagh 2007 [59] & Y & Y & Y & Y & U & Y & N & Y & $\mathrm{N}$ & N & $\mathrm{N}$ \\
\hline Wijnen 1996 [60] & Y & Y & Y & Y & U & Y & N & $\mathrm{N}$ & $\mathrm{N}$ & Y & $\mathrm{N}$ \\
\hline Ma 1996 [61] & Y & Y & Y & Y & U & Y & N & Y & $\mathrm{N}$ & N & $N$ \\
\hline Zhao 1995 [62] & Y & Y & Y & Y & U & Y & N & Y & $\mathrm{N}$ & N & $\mathrm{N}$ \\
\hline Ma 1994 [63] & Y & Y & Y & Y & U & Y & N & N & $\mathrm{N}$ & N & $N$ \\
\hline Kanoh 1993 [64] & Y & Y & Y & Y & U & $N$ & N & Y & $N$ & N & $N$ \\
\hline Siwińska 1998 [65] & Y & Y & Y & Y & U & Y & N & N & $N$ & N & $\mathrm{N}$ \\
\hline Siwińska 1999 [66] & Y & Y & Y & Y & U & Y & N & $N$ & $\mathrm{~N}$ & N & $N$ \\
\hline Fiala 2001 [67] & Y & Y & Y & Y & U & Y & N & N & $\mathrm{N}$ & $\mathrm{N}$ & $N$ \\
\hline
\end{tabular}

(1) Define the source of information (survey, record review); (2) list inclusion and exclusion criteria for exposed and unexposed subjects (cases and controls) or refer to previous publications; (3) indicate time period used for identifying patients; (4) indicate whether or not subjects were consecutive if not population-based; (5) indicate if evaluators of subjective components of study were masked to other aspects of the status of the participants; (6) describe any assessments undertaken for quality assurance purposes (e.g., test/retest of primary outcome measurements); (7) explain any patient exclusions from analysis; (8) describe how confounding was assessed and/or controlled; (9) if applicable, explain how missing data were handled in the analysis; (10) summarize patient response rates and completeness of data collection; (11) clarify what follow-up, if any, was expected and the percentage of patients for which incomplete data or follow-up was obtained. $Y$ yes, $N$ no, $U$ unclear 
Table 3 Concentration of 11 PAHs metabolites in children and adolescents

\begin{tabular}{llllll}
\hline Metabolites & $\begin{array}{l}\text { No. of } \\
\text { studies }\end{array}$ & \multicolumn{4}{l}{ Concentrations in different age groups (Mean \pm SD, $\mu \mathrm{mol} / \mathrm{mol}$ Cre.) } \\
\cline { 3 - 6 } & 37 & $0.24 \pm 0.35$ & $6-11$ years & $12-20$ years & $0.18 \pm .0 .52$ \\
1-OHPyr & 4 & - & $0.45 \pm 0.75$ & $1.95 \pm 2.56$ & $0.38 \pm 0.98$ \\
1-OHNap & 7 & - & $1.78 \pm 3.07$ & $2.37 \pm 5.34$ & $1.90 \pm 2.78$ \\
2-OHNap & 6 & - & $2.18 \pm 2.67$ & $0.38 \pm 1.38$ & $2.32 \pm 4.83$ \\
2-OHFlu & 2 & - & $1.48 \pm 0.20$ & $0.09 \pm 0.22$ & $0.81 \pm 1.54$ \\
3-OHFlu & 2 & - & $0.07 \pm 0.19$ & $0.15 \pm 0.36$ & $0.08 \pm 0.21$ \\
9-OHFlu & 3 & - & $0.11 \pm 0.20$ & $0.07 \pm 0.11$ & $0.14 \pm 0.33$ \\
1-OHPhe & 4 & - & $0.09 \pm 0.17$ & $0.06 \pm 0.07$ & $0.08 \pm 0.13$ \\
2-OHPhe & 5 & - & $0.07 \pm 0.19$ & $0.07 \pm 0.10$ & $0.07 \pm 0.12$ \\
3-OHPhe & 8 & - & $0.14 \pm 0.20$ & $0.02 \pm 0.05$ & $0.09 \pm 0.14$ \\
4-OHPhe & 4 & $1.90 \pm 1.20$ & $0.04 \pm 0.15$ & $0.16 \pm 0.45$ & $0.03 \pm 0.10$ \\
9-OHPhe & 37 & $0.02 \pm 0.02$ & $0.29 \pm 0.76$ \\
\hline
\end{tabular}

The concentration of 2-OHNap, 1-OHNap, 2-OHFlu, 3-OHFlu, 9-OHFlu, 1-OHPhe, 2-OHPhe, 3-OHPhe, and 4-OHPhe in children aged under 6 years were not pooled due to the lack of data.

were higher than those in 12 to 20 years age groups. Details are shown in Table 3.

\section{Comparison of PAHs metabolites levels in various children groups \\ 1-OHPyr}

Living environment and 1-OHPyr levels Meta-analysis based on 16 studies [27, 32, 33, 37-49] indicated that the level of 1-OHPyr was higher in children living with higher environmental exposure than that in children living with lower exposure $(\mathrm{SMD}=0.21,95 \% \mathrm{CI}=$ $0.03 \sim 0.40$ ) (Fig. 3). A random effects model was adopted $\left(P<0.05, I^{2}=82 \%\right)$. Subgroup analyses by countries, ages, gender, type of data, study period, and sample collection seasons are shown in Table 4. Statistical differences in levels of 1-OHPyr between higher exposure group and lower exposure group were found in subgroups of developing countries $(\mathrm{SMD}=0.37,95 \% \mathrm{CI}=$ $0.03 \sim 0.72)$, both genders $(\mathrm{SMD}=0.25, \quad 95 \% \quad \mathrm{CI}=$ $0.04 \sim 0.46$ ), and study period in 2001-2010 (SMD $=0.27$, $95 \% \mathrm{CI}=0.04 \sim 0.50)$.

Environmental tobacco smoke and 1-OHPyr levels Meta-analysis based on six studies [29, 32, 35, 41, 45, 66] indicated that the level of 1-OHPyr was higher in children exposed to ETS than that in children not exposed to ETS $(\mathrm{SMD}=0.31,95 \% \mathrm{CI}=0.08 \sim 0.54) \quad$ (Fig. 4). A random effects model was adopted $\left(P<0.05, I^{2}=59 \%\right)$. The pooled results were not changed in each individual sensitivity analysis by the leaving one out approach.

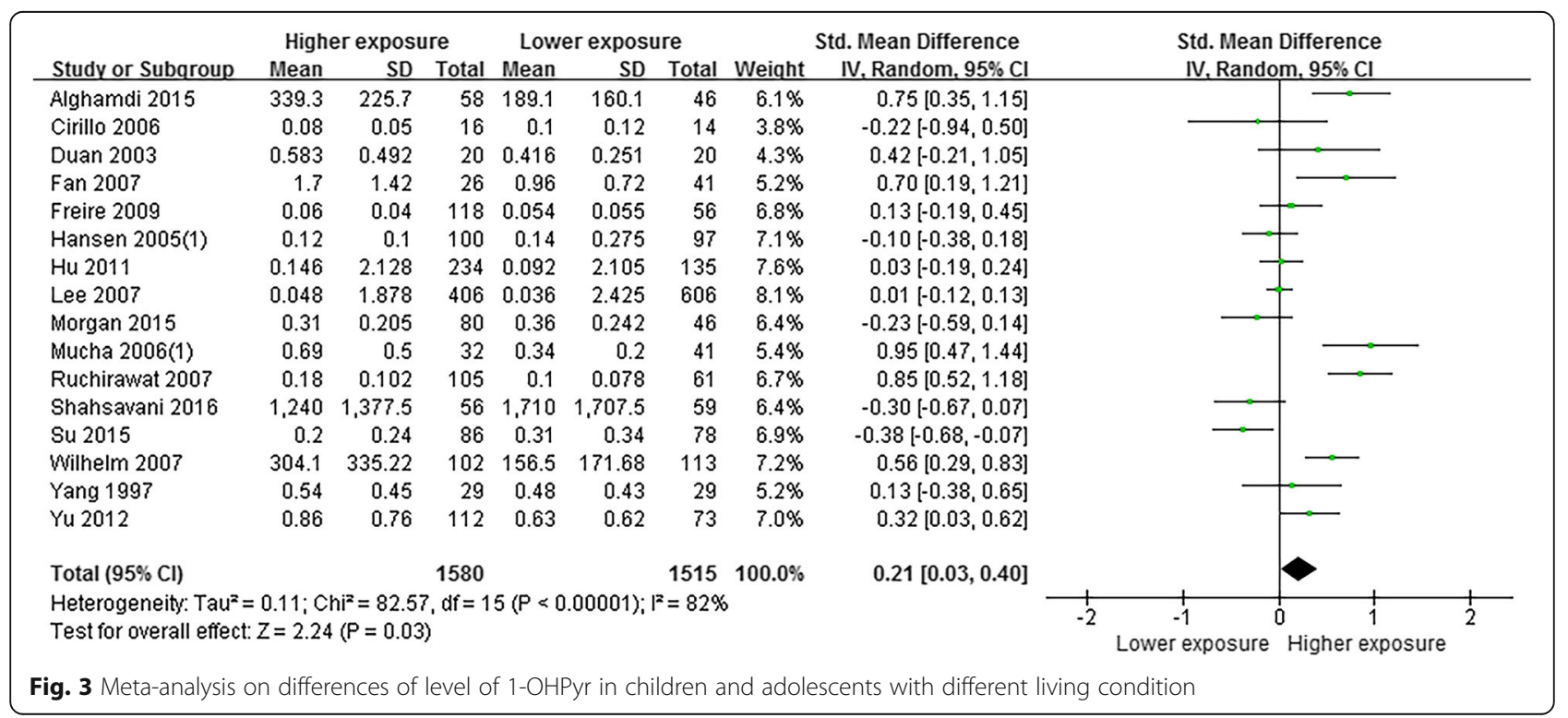


Table 4 Subgroup analysis on differences of level of 1-OHPyr in children and adolescents with different living condition

\begin{tabular}{|c|c|c|c|c|c|c|c|c|c|c|c|c|}
\hline \multirow[t]{2}{*}{ Character } & \multirow[t]{2}{*}{ Subgroup } & \multirow{2}{*}{$\begin{array}{l}\text { No. } \\
\text { studies }\end{array}$} & \multirow[t]{2}{*}{ SMD } & \multicolumn{2}{|l|}{$95 \% \mathrm{Cl}$} & \multicolumn{3}{|c|}{ Heterogeneity } & \multicolumn{2}{|c|}{ Begg's test } & \multicolumn{2}{|c|}{ Egger's test } \\
\hline & & & & Lower & $\overline{\text { Upper }}$ & $\overline{x^{2}}$ & $P$ & $P^{2}(\%)$ & $\bar{z}$ & $P$ & $t$ & $P$ \\
\hline Overall & & 16 & 0.21 & 0.03 & 0.40 & 82.57 & $<0.01$ & 82 & 0.77 & 0.44 & 1.32 & 0.21 \\
\hline \multirow[t]{2}{*}{ Countries (Additional file 1: Figure S1) } & Developed & 7 & 0.06 & -0.12 & 0.23 & 18.05 & $<0.01$ & 67 & -0.45 & 0.65 & 0.05 & 0.98 \\
\hline & Developing & 9 & 0.37 & 0.03 & 0.72 & 53.81 & $<0.01$ & 85 & 0.21 & 0.84 & 3.28 & 0.41 \\
\hline \multirow[t]{2}{*}{ Age (Additional file 1: Figure S2) } & $\leq 6$ years & 3 & 0.26 & -0.33 & 0.86 & 14.51 & $<0.01$ & 86 & 0.00 & 1.00 & 1.15 & 0.46 \\
\hline & $7-18$ years & 11 & 0.19 & -0.05 & 0.43 & 56.93 & $<0.01$ & 82 & 0.47 & 0.64 & 0.98 & 0.35 \\
\hline \multirow[t]{2}{*}{ Gender (Additional file 1: Figure S3) } & Boys only & 3 & 0.03 & -0.40 & 0.45 & 4.42 & 0.11 & 55 & 1.57 & 0.12 & 5.58 & 0.02 \\
\hline & Both genders & 13 & 0.25 & 0.04 & 0.46 & 76.37 & $<0.01$ & 84 & 1.10 & 0.27 & 2.35 & 0.17 \\
\hline \multirow[t]{2}{*}{ Data (Additional file 1: Figure S4) } & Original & 12 & 0.21 & 0.00 & 0.42 & 55.76 & $<0.01$ & 80 & 0.69 & 0.49 & 1.70 & 0. \\
\hline & Estimating & 4 & 0.22 & -0.24 & 0.69 & 25.27 & $<0.01$ & 88 & -0.68 & 0.49 & 0.58 & 0.96 \\
\hline \multirow[t]{3}{*}{ Study period (Additional file 1: Figure S5) } & 1994-2000 & 5 & 0.25 & -0.16 & 0.66 & 25.49 & $<0.01$ & 84 & 0.24 & 0.81 & 1.63 & 0. \\
\hline & $2001-2010$ & 8 & 0.27 & 0.04 & 0.50 & 31.19 & $<0.01$ & 78 & 0.87 & 0.39 & 2.17 & 0.16 \\
\hline & $2011-2015$ & 3 & 0.02 & -0.66 & 0.69 & 21.24 & $<0.01$ & 91 & 1.04 & 0.30 & 19.77 & 0.40 \\
\hline \multirow[t]{3}{*}{ Sample collection season (Additional file 1: Figure S6) } & Spring & 5 & 0.37 & -0.04 & 0.77 & 38.48 & $<0.01$ & 90 & 1.47 & 0.14 & 3.61 & 0.2 \\
\hline & Winter & 5 & 0.12 & -0.11 & 0.35 & 5.83 & 0.21 & 31 & 0.00 & 1.00 & 0.18 & 0.93 \\
\hline & Unclear & 6 & 0.17 & -0.19 & 0.53 & 37.93 & $<0.01$ & 87 & 0.94 & 0.35 & 3.28 & 0.5 \\
\hline
\end{tabular}

Gender and 1-OHPyr levels Meta-analysis based on 1549 subjects [26-35] indicated that the level of 1OHPyr in girls were higher than that in boys (SMD = -0.72 , 95\% CI $=-1.28 \sim-0.15$ ) (Fig. 5). A random effects model was adopted $\left(P<0.05, I^{2}=96 \%\right)$. However, after removing Kang 2002 [28] in sensitivity analysis, the pooled data changed to no statistical difference between genders $(\mathrm{SMD}=-0.01,95 \% \mathrm{CI}=$ $-0.11 \sim 0.10$ ), and the heterogeneity reduced to $0 \%$ (Fig. 6).

Age and 1-OHPyr levels Four studies [50-53] pooled the data of 1-OHPyr in different age group, showing that the concentration of 1-OHPyr in the 6 11 years group was higher than that in 12 19 years group $(\mathrm{SMD}=0.16,95 \% \mathrm{CI}=0.09 \sim 0.23)$, (Fig. 7). The fixed effects model was adopted $\left(P>0.05, I^{2}=0 \%\right)$.

\section{2-OHNap}

Living environment and 2-OHNap levels Two studies $[40,46]$ reported the concentration of 2-OHNap. The pooled data showed that the concentration of 2-OHNap detected in children living with higher PAHs exposure was higher than that in children with lower exposure $(\mathrm{SMD}=0.27,95 \% \mathrm{CI}=0.01 \sim 0.53)$; the fixed effects model was adopted $\left(P>0.05, I^{2}=35 \%\right)$, (Fig. 8).

Gender and 2-OHNap levels Two studies [28, 30] pooled the data of concentration of 2-OHNap, showing that there were no statistical differences in the level of 2-OHNap between boys and girls (SMD = $0.01,95 \% \mathrm{CI}=-0.20 \sim 0.22)$; the fixed effects model was adopted $\left(P>0.05, I^{2}=0 \%\right)$, (Fig. 9).

\section{Other metabolites}

Two studies [40,46] pooled the data of 1-OHNap and 2-OHPhe, and three studies [37, 40, 46] pooled the data of 3-OHPhe and 4-OHPhe. The pooled data showed no significant differences in urinary concentration of 1-OHNap, 2-OHPhe and 3-OHPhe between the groups living with higher/lower environmental exposure (Table 5),

\begin{tabular}{|c|c|c|c|c|c|c|c|c|c|c|}
\hline \multirow[b]{2}{*}{ Study or Subqroup } & \multicolumn{3}{|c|}{ Exposed to ETS } & \multicolumn{3}{|c|}{ Not exposed to ETS } & \multirow[b]{2}{*}{ Weight } & \multirow{2}{*}{$\begin{array}{l}\text { Std. Mean Difference } \\
\text { IV. Random, } 95 \% \mathrm{Cl}\end{array}$} & \multirow{2}{*}{\multicolumn{2}{|c|}{$\begin{array}{l}\text { Std. Mean Difference } \\
\text { IV, Random, } 95 \% \mathrm{Cl}\end{array}$}} \\
\hline & Mean & SD & Total & Mean & SD & Total & & & & \\
\hline Freire 2009 & 0.063 & 0.055 & 81 & 0.052 & 0.05 & 93 & $19.9 \%$ & $0.21[-0.09,0.51]$ & & \\
\hline Mielzynska 2006 & 0.56 & 0.25 & 40 & 0.51 & 0.4 & 26 & $12.7 \%$ & $0.16[-0.34,0.65]$ & - & \\
\hline Morgan 2015 & 0.34 & 0.2 & 25 & 0.32 & 0.23 & 101 & $14.5 \%$ & $0.09[-0.35,0.53]$ & & \\
\hline Shahsavani 2016 & 2,230 & 1,108 & 38 & 1,190 & 1,138 & 77 & $15.6 \%$ & $0.92[0.51,1.32]$ & & 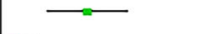 \\
\hline Siwińska 1999 & 0.537 & 0.693 & 286 & 0.432 & 0.707 & 126 & $23.9 \%$ & $0.15[-0.06,0.36]$ & & $f=-$ \\
\hline Yue 2010(1) & 0.44 & 0.22 & 27 & 0.35 & 0.21 & 53 & $13.5 \%$ & $0.42[-0.05,0.89]$ & & \\
\hline Total $(95 \% \mathrm{Cl})$ & & & 497 & & & 476 & $100.0 \%$ & $0.31[0.08,0.54]$ & & \\
\hline \multicolumn{9}{|c|}{$\begin{array}{l}\text { Heterogeneity: } \text { Tau }^{2}=0.05 ; \mathrm{Chi}^{2}=12.33, \mathrm{df}=5(P=0.03) ; I^{2}=59 \% \\
\text { Test for overall effect: } Z=2.60(P=0.009)\end{array}$} & $\begin{array}{ccc}1 & 1 & 1 \\
-2 & -1 & 1 \\
\text { Higher in not exposure }\end{array}$ & 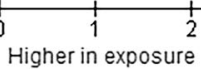 \\
\hline
\end{tabular}




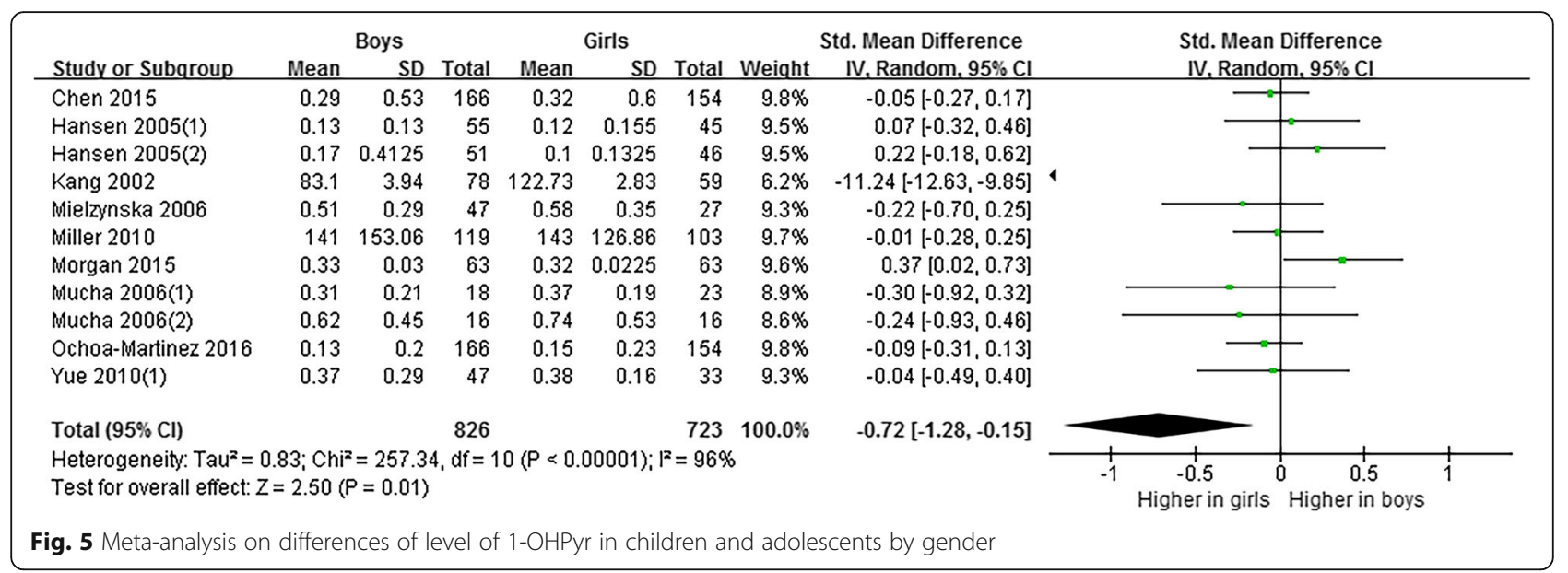

while the concentration of 4-OHPhe detected in children living with lower exposure was higher than that in children with higher exposure $(\mathrm{SMD}=-0.48,95 \%$ $\mathrm{CI}=-0.69 \sim-0.28$, Additional file 1: Figure S11). When the data of Fan 2007 [40] was removed in sensitivity analysis of 3-OHPhe, the pooled result altered $(\mathrm{SMD}=-0.34,95 \% \mathrm{CI}=-0.57 \sim-0.12)$, and the heterogeneity reduced to $0 \%$ (Additional file 1: Figure S10).

\section{Discussion}

PAHs are widely diffused in the environment, and there is a high risk for human to expose to it. Knowing the exposure level of PAHs and comparing the levels in various groups can provide basic data for the environment pollution control, and can also contribute to the further study on association of PAHs with human health. A total of 12697 children were enrolled in this study, covering 19 countries or areas of five continents, detecting 11 kinds of PAHs urinary metabolites. To the best of our knowledge, this is the first systematic review and metaanalysis to estimate the total level of non-occupational internal exposure of PAHs and to compare exposure levels of PAHs metabolites in various groups of children and adolescents.

The present study pooled the total concentration of 11 PAHs metabolites in children and adolescents based on 37 studies including 10321 children. 1-OHPyr is the most widely used biomarker of PAHs, and several [68-70] studies reported the occupational exposure limit (OEL) of 1-OHPyr. However, there is lack of the limit value for general population, nor for children. Jongeneeleen et al. [68] suggested that the reference value in non-occupational people is $0.24 \mu \mathrm{mol} / \mathrm{mol}$ creatinine and $0.76 \mu \mathrm{mol} / \mathrm{mol}$ creatinine for non-smokers and smokers, respectively; however, the pooled value of 1-OHPyr in children in this study was $0.38 \mu \mathrm{mol} / \mathrm{mol}$ creatinine, which is higher than the reference value. 1-OHNap and 2-OHNap were the highest levels of PAHs metabolites in the urine of children, with the pooled value of 1.90 and $2.32 \mu \mathrm{mol} / \mathrm{mol}$ creatinine, respectively. Except for 1-OHPyr, all the other ten PAHs biomarkers have no reference or limit value; the pooled concentration in this study could provide a reference for future research and evaluation on PAHs

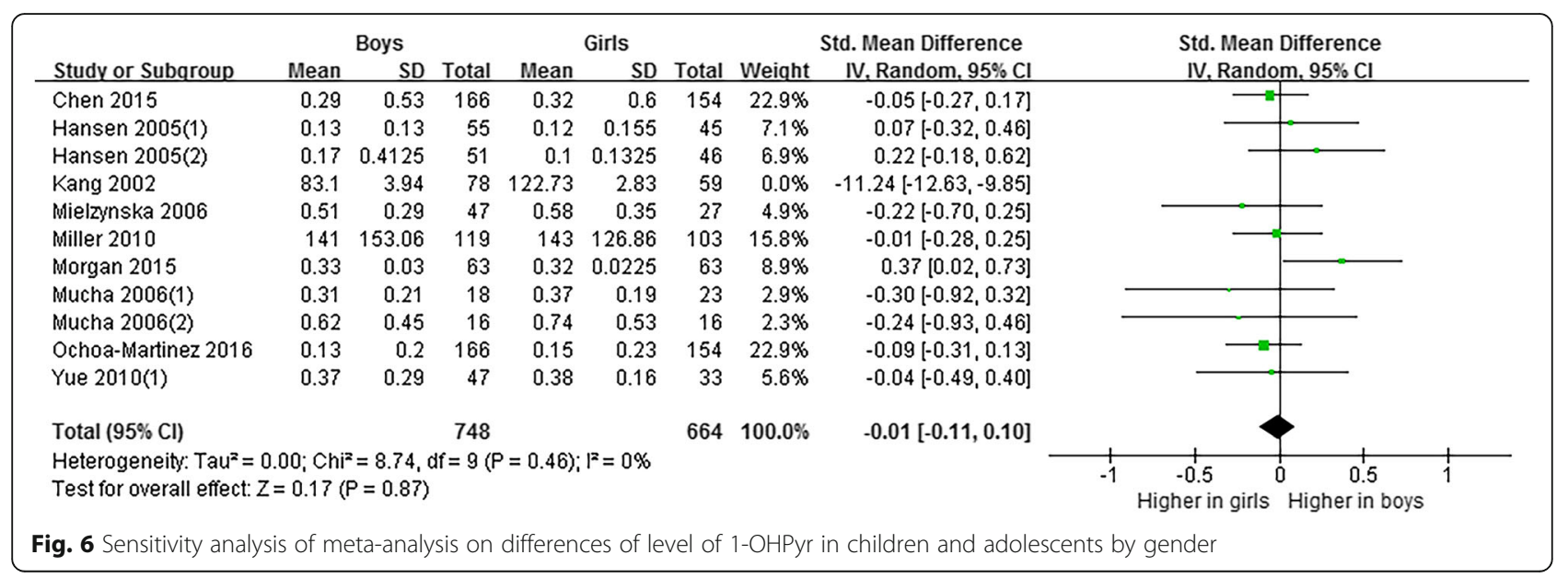




\begin{tabular}{|c|c|c|c|c|c|c|c|c|c|c|c|c|}
\hline \multirow[b]{2}{*}{ Study or Subgroup } & \multicolumn{2}{|r|}{$6 \sim 11$} & \multicolumn{3}{|r|}{$12 \sim 19$} & \multirow[b]{2}{*}{ Total } & \multirow[b]{2}{*}{ Weight } & \multirow{2}{*}{$\begin{array}{l}\text { Std. Mean Difference } \\
\text { IV, Random, } 95 \% \mathrm{Cl}\end{array}$} & \multicolumn{4}{|c|}{ Std. Mean Difference } \\
\hline & Mean & $\mathrm{SD}$ & Total & Mean & SD & & & & & IV, Randon & m. $95 \% \mathrm{Cl}$ & \\
\hline Heudorf 2001 & 142 & 118 & 261 & $12 ?$ & 37 & 110 & $10.0 \%$ & $0.14[-0.08,0.36]$ & & & & \\
\hline Huang 2006 & 94.1 & 171.13 & 310 & 71.5 & 161.84 & 693 & $23.3 \%$ & $0.14[0.00,0.27]$ & & & & \\
\hline Huang 2014 & 0.73 & 1.29 & 411 & 0.64 & 0.93 & 516 & $29.6 \%$ & $0.12[-0.01,0.25]$ & & & - -들 & \\
\hline Li 2008 & 67 & 100.37 & 387 & 44 & 103.74 & 735 & $32.7 \%$ & $0.22[0.10,0.35]$ & & & - - & \\
\hline Total $(95 \% \mathrm{Cl})$ & & & 1369 & & & 2054 & $100.0 \%$ & $0.16[0.09,0.23]$ & & & & \\
\hline $\begin{array}{l}\text { Heterogeneity: Tau } \\
\text { Test for overall effect }\end{array}$ & $\begin{array}{l}0.00 ; \mathrm{Cl} \\
\mathrm{Z}=4.44\end{array}$ & $\begin{aligned} \mathrm{i}^{2} & =1.59 \\
\langle\mathrm{P} & <0.0\end{aligned}$ & $\begin{array}{l}d f=3 \\
0001)\end{array}$ & $(P=$ & j); $F^{2}=0$ & & & & -0.5 & $-0.2512 \sim 19$ & $0_{6 \sim 11} 0.25$ & 0.5 \\
\hline
\end{tabular}

Fig. 7 Meta-analysis on differences of levels of 1-OHPyr in children and adolescents in different age groups

biomarkers in children. Compared to the general population, the levels of 1-OHPyr and 3-OHPhe in this study were higher than those in the USA [56] and lower than those in China [51]. Contrarily, the levels of 1-OHNap and 2-OHNap were higher than those in China [51] and lower than those in the USA [56].

This study found that level of 1-OHPyr in children living with higher environmental exposure was higher than that in children living with lower exposure. The level of 1-OHPyr in urine is influenced by many factors, including biological variability between subjects (e.g., age, gender, race, health status, nutritional status), cultural differences (e.g., environment, diet, smoking, alcohol, occupation), and variation in the laboratory techniques applied (e.g., sampling design, protocols, analytical precision of the measurement) [21]. Subgroup analysis was conducted to explore the potential confounding factors in this meta-analysis. We found that compared with children living in lower PAHs exposure area, children living with higher PAHs exposure had a higher level of 1-OHPyr in subgroup of developing countries and both genders. The results consist with a cross-sectional study [71] conducted in general population from seven Asian countries. Several studies [72-74] have shown that the concentration of 1-OHPyr was influence by smoking. In this study, we found that the level of 1-OHPyr also higher in children who was exposed to the ETS. The reason was most because of inducing effect of cigarette smoke on CPYs [75]. As for the gender, the pooled estimates showed that the level of 1-OHPyr has statistical differences between boys and girls with heterogeneity of $96 \%$, which may not necessarily mean that the level of 1-OHPyr in girls was higher than that in boys. The inconsistency may be related to the study of Kang et al. [28]; children included in this study have sample bias. First, the study chose four schools which had different PAHs exposure levels in air. Second, the study only enrolled boys in a lower exposure school and enrolled girls in a higher exposure school. Thus, the level of 1-OHPyr in girls in this study was higher than boys. After removing Kang et al. [28] in metaanalysis, the pooled data altered, and the heterogeneity was reduced to $0 \%$. Therefore, we suggest that the levels of 1-OHPyr were not statistically different between boys and girls. Moreover, the pooled data showed that the level of 1-OHPyr in children aged 6 to 11 years was higher than that in age group of $12 \sim 19$ years. Behaviors that are common in childhood but are not observed in adults and the biological characteristics of young children may be reasons that lower age group has higher level of 1-OHPyr. On the one hand, young children prefer to play and crawl around on the floor and ground, increasing the risk of inhaling or dermally absorbing toxicants from particles, vapors present in carpets and soil [76]. On the other hand, previous studies [77, 78] have indicated that the metabolism of PAHs in children is different from that in adults, and children seem more susceptible to PAHs.

We found that the concentration of 2-OHNap detected in children living with higher environmental PAH exposure was higher than that in the lower exposure area. Li et al. [52] reported that concentration of 2-OHNap was well correlated with total PAH exposure, which indicated the higher level of PAHs in air, and the higher level in urine. There were no statistical differences in the levels of

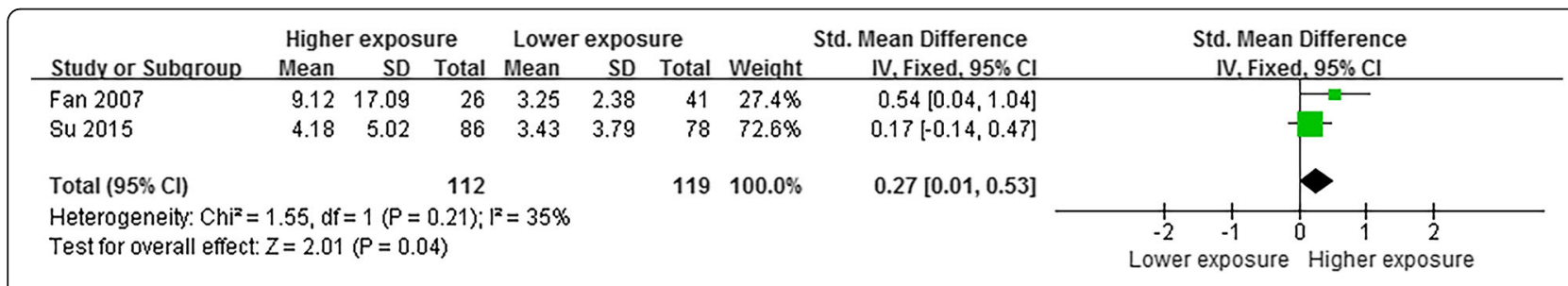

Fig. 8 Meta-analysis on differences of level of 2-OHNap in children and adolescents with different living condition 


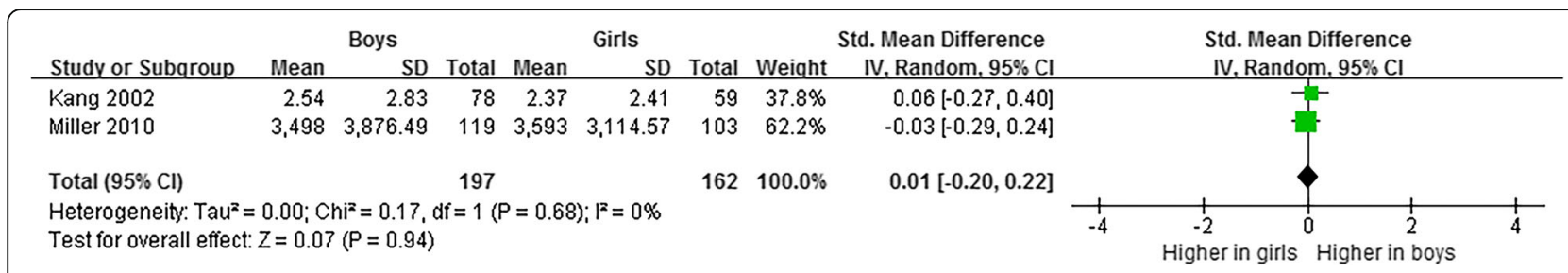

Fig. 9 Meta-analysis on differences of level of 2-OHNap in children and adolescents by gender

2-OHNap between boys and girls. However, only two studies were included in the analysis, which may not reflect the real differences. Therefore, studies on 2-OHNap still need to be done to identify the potential differences between genders.

The meta-analysis only compared the concentration of other PAHs metabolites in children living with different environmental exposure. The pooled data showed that the levels of 3-OHPhe and 4-OHPhe detected in children living with lower environmental exposure were higher than those in the higher exposure area. Scinicariello et al. [79] noted that the main source of exposure of the larger PAHs (such as phenanthrene) is dietary, which could lead to the higher concentration of hydroxyphenanthrene found in lower exposure environment.

We conducted a comprehensive search to cover all the available studies measuring PAHs metabolites in children with non-occupational exposure to estimate the level of the PAHs internal exposure and to compare the levels of PAHs internal exposure in various children groups, the findings of which may provide a reference for studies in this area. However, several limitations still need to be considered when interpreting and generalizing the present results. First, some data had been recalculated before putting in the analysis which may influence the accuracy of the pooled estimates. The concentration of 2-OHNap, 1-OHNap, 2-OHFlu, 3-OHFlu, 9-OHFlu, 1-OHPhe, 2-OHPhe, 3-OHPhe, and 4-OHPhe in children aged under 6 years were not pooled due to the lack of data. Second, the level of PAHs in children may be abnormal distribution, and a mean value measures the central tendency, which could also lead to a bias in the estimating of total PAHs metabolites level and meta-analysis. Third, subgroup analyses were conducted by countries, gender, age, type of data, study period, and sample collection season in this study but the heterogeneity were not decrease obviously. In addition, heterogeneity that comes from ethnicity diversity, food intake differences, sample size differences, and health status could not be analyzed in the current meta-analysis, which also needs to be considered when interpreting the pooled results. Besides, we found that combustion of industrial sources and automobile exhaust were the main exposure sources of higher environmental exposure group in this study. However, the subgroup analysis grouping by kind of exposure sources were not conducted due to only one study [44] has tested the 1-OHPyr of children living near to main roads. Fourth, meta-analysis on differences of 1-OHPyr concentration in children and adolescents by age were conducted in children aged 6 to 11 years and 12 to 19 years. The cut-off point of 11 years may not represent a sharp limit, and the difference of levels of 1-OHPyr in children under 6 years group were not analyzed. Further, although majority of children of our included studies were recruited from schools, a small proportion of adolescents (12.11\%) aged 12 to 20 years were sampled based on population registry, which may lead to including young people as "non-occupationally exposed" with the same likelihood of school children. Finally, except for 1-OHPyr, there were few studies with small

Table 5 Urinary concentration of four PAH metabolites between living with higher environmental exposure group and living with lower environmental exposure group

\begin{tabular}{|c|c|c|c|c|c|c|c|}
\hline \multirow[t]{2}{*}{ Metabolites } & \multirow{2}{*}{$\begin{array}{l}\text { No. of } \\
\text { studies }\end{array}$} & \multirow[t]{2}{*}{ Model } & \multirow[t]{2}{*}{ SMD $(95 \% C l)$} & \multirow[t]{2}{*}{$p$} & \multicolumn{3}{|c|}{ Heterogeneity } \\
\hline & & & & & $x^{2}$ & $p$ & $R^{2}$ \\
\hline 1-OHNap (Additional file 1: Figure S7) & 2 & Fixed effects & $0.35[-1.28,1.99]$ & 0.67 & 1.59 & 0.21 & $37 \%$ \\
\hline 2-OHPhe (Additional file 1: Figure S8) & 2 & Random effects & $0.02[-0.11,0.16]$ & 0.75 & 5.30 & 0.02 & $81 \%$ \\
\hline \multirow[t]{2}{*}{ 3-OHPhe (Additional file 1: Figure S9) } & 3 & Random effects & $-0.16[-0.55,0.23]$ & 0.42 & 6.46 & 0.04 & $69 \%$ \\
\hline & $2^{a}$ & Fixed effects & $-0.34[-0.57,-0.12]$ & 0.003 & 0.29 & 0.59 & $0 \%$ \\
\hline 4-OHPhe (Additional file 1: Figure S11) & 3 & Fixed effects & $-0.48[-0.69,-0.28]$ & $<0.01$ & 1.45 & 0.48 & $0 \%$ \\
\hline
\end{tabular}

${ }^{\mathrm{a}}$ Sensitivity analysis of meta-analysis on differences of levels of 3-OHPhe in children and adolescents with different living conditions (Additional file 1: Figure S10) 
sample size reported on other ten PAHs metabolites, thus the internal exposure levels in various children groups cannot be accurately analyzed.

\section{Conclusion}

In summary, 1-OHPyr is the most widely used biomarker of PAHs. The pooled value of 1-OHPyr in children in this study was higher than the reported reference value of non-occupational people who do not smoke. The present meta-analysis suggests that the level of 1-OHPyr in children and adolescent were in relative high status, especially among the children at younger age. The internal diversity of PAHs exists in children and adolescents. Children and adolescents living with higher environmental exposure and exposed to ETS have higher concentration of 1-OHPyr. There were few studies reported on other PAHs metabolites such as 2-OHNap, 2-OHFlu, 3-OHPhe, and 4-OHPhe, thus more attention needs to be paid on those metabolites in future studies.

\section{Additional file}

Additional file 1 Figure S1. Subgroup analysis by countries on differences of levels of 1-OHPyr in children and adolescents with different living conditions. Figure $\mathbf{S 2}$. Subgroup analysis by age groups on differences of levels of 1-OHPyr in children and adolescents with different living conditions. Figure S3. Subgroup analysis by gender on differences of levels of 1-OHPyr in children and adolescents with different living conditions. Figure S4. Subgroup analysis by type of data on differences of levels of 1-OHPyr in children and adolescents with different living conditions. Figure S5. Subgroup analysis by study period on differences of levels of 1-OHPyr in children and adolescents with different living conditions. Figure S6. Subgroup analysis by sample collection season on differences of levels of 1-OHPyr in children and adolescents with different living conditions. Figure S7. Meta-analysis on differences of levels of 1OHNap in children and adolescents with different living conditions. Figure S8. Meta-analysis on differences of levels of 2-OHPhe in children and adolescents with different living conditions. Figure S9. Meta-analysis on differences of levels of 3-OHPhe in children and adolescents with different living conditions. Figure S10. Sensitivity analysis of metaanalysis on differences of levels of 3-OHPhe in children and adolescents with different living conditions. Figure S11. Meta-analysis on differences of levels of 4-OHPhe in children and adolescents with different living conditions. (DOCX $194 \mathrm{~kb})$

\footnotetext{
Abbreviations

95\% Cl: 95\% Confidence interval; AHRQ: Agency for Healthcare Research and Quality; BaP: Benzo[a]pyrene; CPYs: Cytochrome P450s; Cre.: Creatinine; ETS: Environmental tobacco smoke; FD: Fluorescence detection; GC: Gas chromatography; HPLC: High-performance liquid chromatography; IARC: International Agency for Research on Cancer; IDHRMS: Isotope dilution high resolution mass spectrometry; MS: Mass spectrometry; NA: Not available; OEL: Occupational exposure limit; OHFlu: Hydroxyfluorene;

OHNap: Hydroxynaphalene; OHPhe: Hydroxyphenanthrene; OHPyr: Hydroxypyrene; PAHs: Polycyclic aromatic hydrocarbons;

PRISMA: Preferred reporting items for systematic reviews and meta-analyses; SD: Standard deviation; SG: Specific gravity; SMD: Standard mean difference; USEPA: The United States Environmental Protection Agency; UV: Ultraviolet
}

\section{Acknowledgments}

The authors are grateful to professors and graduate students of health statistics from school of Public Health and Management, Chongqing Medical University for providing assistance about statistical analysis.

\section{Authors' contributions}

$\mathrm{QL}, \mathrm{XH}$, and $\mathrm{XD}$ conceived and designed the study. XH, XD, WL, SL, and BY designed the selection criteria. $\mathrm{XH}, \mathrm{XD}$, and $\mathrm{QL}$ screened literature and extracted data. XH, XD, YC, WL, SL, BY, and QL preformed the statistical analysis. XH and QL drafted and revised the manuscript. All authors read and approved the final manuscript.

\section{Funding}

This research was funded by the National Youth Science Fund Project of China, grant number 81502825 .

\section{Availability of data and materials}

Please contact author for data requests.

Ethics approval and consent to participate

Not applicable.

\section{Consent for publication}

Not applicable.

\section{Competing interests}

The authors declare that they have no competing interests.

Received: 3 April 2019 Accepted: 12 July 2019

Published online: 27 July 2019

\section{References}

1. Ferrari S, Mandel F, Berset JD. Quantitative determination of 1hydroxypyrene in bovine urine samples using high-performance liquid chromatography with fluorescence and mass spectrometric detection. Chemosphere. 2002;47:173-82.

2. Mumtaz MM, George JD, Gold KW, Cibulas W, DeRosa CT. ATSDR evaluation of health effects of chemicals. IV. Polycyclic aromatic hydrocarbons (PAHs): understanding a complex problem. Toxicol Ind Health. 1996;12:742-971.

3. Ramesh A, Walker SA, Hood DB, Guillén MD, Schneider K, Weyand EH. Bioavailability and risk assessment of orally ingested polycyclic aromatic hydrocarbons. Int J Toxicol. 2004;23:301-33.

4. Boström CE, Gerde P, Hanberg A, Jernström B, Johansson C, Kyrklund T, et al. Cancer risk assessment, indicators, and guidelines for polycyclic aromatic hydrocarbons in the ambient air. Environ Health Perspect. 2002;110(Suppl 3):451-88

5. Mumtaz M, George J. Toxicological profile for polycyclic aromatic hydrocarbons. Agency for Toxic Substances and Disease Registry. 1995. http://www.atsdr.cdc.gov/toxprofiles/tp69.pdf. Accessed 25 Jan 2018.

6. Grainger J, Huang W, Patterson DG Jr, Turner WE, Pirkle J, Caudill SP, et al. Reference range levels of polycyclic aromatic hydrocarbons in the US population by measurement of urinary monohydroxy metabolites. Environ Res. 2006;100:394-423.

7. International Agency for Research on Cancer. IARC monographs on the evaluation of carcinogenic risks to humans. Lyon: International Agency for Research on Cancer; 2010.

8. Hoseini M, Yunesian M, Nabizadeh R, Yaghmaeian K, Ahmadkhniha R, Rastkari N, et al. Characterization and risk assessment of polycyclic aromatic hydrocarbons (PAHs) in urban atmospheric particulate of Tehran, Iran. Environ Sci Pollut Res Int. 2016;23:1820-32.

9. Yang L, Zhou Y, Sun H, Lai H, Liu C, Yan K, et al. Dose-response relationship between polycyclic aromatic hydrocarbon metabolites and risk of diabetes in the general Chinese population. Environ Pollut. 2014;195:24-30.

10. Brocato J, Sun H, Shamy M, Kluz T, Alghamdi MA, Khoder Ml, et al. Particulate matter from Saudi Arabia induces genes involved in inflammation, metabolic syndrome and atherosclerosis. J Toxicol Environ Health A. 2014;77:751-66.

11. Feng $Y$, Sun $H$, Song $Y$, Bao J, Huang $X$, Ye J, et al. A community study of the effect of polycyclic aromatic hydrocarbon metabolites on heart rate variability based on the Framingham risk score. Occup Environ Med. 2014;71:338-45. 
12. Gamboa RT, Gamboa AR, Bravo AH, Ostrosky WP. Genotoxicity in child populations exposed to polycyclic aromatic hydrocarbons (PAHs) in the air from Tabasco, Mexico. Int J Environ Res Public Health. 2008;5:349-55.

13. Svecova V, Rossner P Jr, Dostal M, Topinka J, Solansky I, Sram RJ. Urinary 8-oxodeoxyguanosine levels in children exposed to air pollutants. Mutat Res. 2009;662:37-43.

14. Perera F, Tang WY, Herbstman J, Tang D, Levin L, Miller R, Ho SM. Relation of DNA methylation of 5-CpG island of ACSL3to transplacental exposure to airbone polycyclic aromatic hydrocarbons and childhood asthma. PLoS One. 2009;4:e4488.

15. Perera F, Li TY, Zhou ZJ, Yuan T, Chen YH, Qu L, et al. Benefits of reducing prenatal exposure to coal burning pollutants to children's neurodevelopment in China. Environ Health Perspect. 2008;116:1396-400.

16. Lee HS, Yang M. Applications of CYP-450 expression for biomonitoring in environmental health. Environ Health Prev Med. 2008;13:84-93.

17. WHO. IPCS Environmental Health Criteria 27. Guidelines on Studies in Environmental Epidemiology. Geneva: WHO; 1983.

18. Shahtaheri S, Ibrahimi L, Golbabaei F, Hosseini M, Fouladi B. Optimization of sample preparation for 1-hydroxypyrene as a major biomarker of exposure to PAHs prior to HPLC. Iran J Public Health. 2005;35:33-41.

19. Jacob J, Seidel A. Biomonitoring of polycyclic aromatic hydrocarbons in human urine. J Chromatogr B Analyt Technol Biomed Life Sci. 2002;778:31-47.

20. Viau MB. Urinary 1-hydroxypyrene as a biomarker of exposure to polycyclic aromatic hydrocarbons: biological monitoring strategies and methodology for determining biological exposure indices for various work environments. Biomarkers. 1999:4:159-87.

21. Hansen AM, Mathiesen L, Pedersen M, Knudsen LE. Urinary 1-hydroxypyrene (1-HP) in environmental and occupational studies-a review. Int J Hyg Environ Health. 2008;211:471-503.

22. Rostom A, Dube C, Cranney A, Saloojee N, Sy R, Garritty C, et al. Celiac disease. Evid Rep Technol Assess. 2004;104:1-6.

23. Hozo SP, Djulbegovic B, Hozo L. Estimating the mean and variance from the median, range, and the size of a sample. BMC Med Res Methodol. 2005;5:13.

24. Higgins JPT, Green S. Cochrane Handbook for Systematic Reviews of Interventions. The Cochrane Collaboration; 2011.

25. Moher D, Liberati A, Tetzlaff J, Altman DG, PRISMA group. Preferred reporting items for systematic reviews and meta-analyses: the PRISMA statement. BMJ. 2009:339:b2535.

26. Chen YT, Huang YK, Luvsan ME, Gombojav E, Ochir C, Bulgan J, et al. The influence of season and living environment on children's urinary 1hydroxypyrene levels in Ulaanbaatar, Mongolia. Environ Res. 2015;137:170-5.

27. Hansen AM, Raaschou-Nielsen O, Knudsen LE. Urinary 1-hydroxypyrene in children living in city and rural residences in Denmark. Sci Total Environ. 2005:347:98-105.

28. Kang JW, Cho SH, Kim H, Lee CH. Correlation of urinary 1-hydroxypyrene and 2-naphthol with total suspended particulates in ambient air in municipal middle-school students in Kore. Arch Environ Health. 2002:57:377-82.

29. Mielzyńska D, Siwińska E, Kapka L, Szyfter K, Knudsen LE, Merlo DF. The influence of environmental exposure to complex mixtures including PAHs and lead on genotoxic effects in children living in upper Silesia, Poland. Mutagenesis. 2006;21:295-304.

30. Miller RL, Garfinkel R, Lendor C, Hoepner L, Li Z, Romanoff L, et al. Polycyclic aromatic hydrocarbon metabolite levels and pediatric allergy and asthma in an inner-city cohort. Pediatr Allergy Immunol. 2010;21:260-7.

31. Jung KH, Lovinsky-Desir S, Perzanowski M, Liu X, Maher C, Gil E, et al. Repeatedly high polycyclic aromatic hydrocarbon exposure and cockroach sensitization among inner-city children. Environ Res. 2015; 140:649-56.

32. Morgan MK, Jones PA, Sobus JR, Chuang JC, Wilson NK. Using urinary biomarkers to evaluate polycyclic aromatic hydrocarbon exposurein 126 preschool children in Ohio. Int J Environ Health Res. 2015;25:628-39.

33. Mucha AP, Hryhorczuk D, Serdyuk A, Nakonechny J, Zvinchuk A, Erdal S, et al. Urinary 1-hydroxypyrene as a biomarker of PAH exposure in 3-year- old Ukrainian children. Environ Health Perspect. 2006;114:603-9.

34. Ochoa-Martinez AC, Orta-Garcia ST, Rico-Escobar EM, Carrizales-Yañez L, Del Campo JD, Pruneda-Alvarez LG, et al. Exposure assessment to environmental chemicals in children from Ciudad Juarez, Chihuahua, Mexico. Arch Environ Contam Toxicol. 2016;70:657-70.

35. Yue Q, Fang RF, Yu ZQ, Sheng GY, Fu JM. Determination of PAHs exposure among unban children in South China. China J Public Health [Zhongguo Gong Gong Wei Sheng]. 2010;26:1078-9.
36. Yue Q. Analysis of hydroxy phenanthrene in urine of kindergarten infants in south China. Environ Sci Technol [Haung Jing Ke Xue Yu Ji Shu]. 2011;34:98-101.

37. Alghamdi MA, Alam MS, Stark C, Mohammed N, Harrison RM, Shamy M, et al. Urinary metabolites of polycyclic aromatic hydrocarbons in Saudi Arabian schoolchildren in relation to sources of exposure. Environ Res. 2015;140:495-501.

38. Cirillo T, Montuori P, Mainardi P, Russo I, Triassi M, Amodio-Cocchieri R. Multi pathway polycyclic aromatic hydrocarbon and pyrene exposure among children living in Campania (Italy). J Environ Sci Health A Tox Hazard Subst Environ Eng. 2006;41:2089-107.

39. X D, Zhao ZH, Ding ZH, Xu J, Wei FS. 10-year trend of urinary I-hydroxy -pyrene in residents of Datong City. Environ Monitor China [Zhongguo Huan Jing Jian Ce]. 2003;19:51-3.

40. Fan RF. Preliminary study of urinary PAHs metabolites for students in pearl river delta and occupational population in Guiyu-an electronic waste recycling site (dissertation). Graduate School of the Chinese Academy of Science: Guangzhou; 2007.

41. Freire C, Abril A, Fernández MF, Ramos R, Estarlich M, Manrique A, et al. Urinary 1-hydroxypyrene and PAH exposure in 4-year-old Spanish children. Sci Total Environ. 2009;407:1562-9.

42. Hu SW, Chan YJ, Hsu HT, Wu KY, Chang Chien GP, Shie RH, et al. Urinary levels of 1-hydroxypyrene in children residing near a coal-fired powerplant. Environ Res. 2011;111:1185-91.

43. Lee MS, Eum KD, Zoh KD, Kim TS, Pak YS, Paek D. 1-hydroxypyrene as a biomarker of $\mathrm{PAH}$ exposure among subjects living in twoseparate regions from a steel mill. Int Arch Occup Environ Health. 2007;80:671-8.

44. Ruchirawat $M$, Settachan D, Navasumrit P, Tuntawiroon J, Autrup $H$. Assessment of potential cancer risk in children exposed to urban air pollution in Bangkok, Thailand. Toxicol Lett. 2007;168:200-9.

45. Shahsavani S, Dehghani M, Hoseini M, Fararouei M. Biological monitoring of urinary 1-hydroxypyrene by PAHs exposure among primary school students in Shiraz, Iran. Int Arch Occup Environ Health. 2017:90:179-87.

46. Su H, Zhao B, Zhang SK, Liu S, Ren MZ, Li J, et al. Internal exposure levels of PAHs of primary school students in Guangzhou. Environ Sci [Huan Jing Ke Xue]. 2015;36:4568-73.

47. Wilhelm M, Eberwein G, Hölzer J, Gladtke D, Angerer J, Marczynski B, et al. Influence of industrial sources on children's health-hot spot studies in North Rhine Westphalia, Germany. Int J Hyg Environ Health. 2007:210:591-9.

48. Yang JZ, Li JY, Shen XL, Zhao ZH. Analysis of urinary I-hydroxypyrene and air polycyclic aromatic hydrocarbons in Jicheng City. Adv Environ Sci [Huan Jing Ke Xue Jin Zhan]. 1997;(supp1):50-5.

49. Yu YJ, Liu ZE, He Y, Zhang YP, Lin HP, Wang Q, et al. Analysis and risk assessment of air benzo (a) pyrene and children urinary 1-hydroxypyrene in Lanzhou City. Acta Sci Circum [Huan Jing Ke Xue Xue Bao]. 2012;32:2332-8.

50. Huang W, Caudill SP, Grainger J, Needham LL, Patterson DG Jr. Levels of 1hydroxypyrene and other monohydroxy polycyclic aromatic hydrocarbons in children: a study based on U.S. reference range values. Toxicol Lett. 2006; 163:10-9.

51. Huang CF, Zhang J, Ding CG, Liu CL, Wang G, Song XK, et al. Polycyclic aromatic hydrocarbons monohydroxy metabolites level in urine of general population in eight provinces of China. Chin J Prev Med [Zhonghua Yu Fang Yi Xue Za Zhi]. 2014;48:102-8.

52. Li Z, Sandau CD, Romanoff LC, Caudill SP, Sjodin A, Needham LL, et al. Concentration and profile of 22 urinary polycyclic aromatic hydrocarbon metabolites in the US population. Environ Res. 2008:107:320-31.

53. Heudorf $U$, Angerer J. Internal exposure to PAHs of children and adults living in homes with parquet flooring containing high levels of PAHs in the parquet glue. Int Arch Occup Environ Health. 2001;74:91-101.

54. Yue Q. The pilot analysis on the exposure level of polycyclic aromatic hydrocarbons in a middle school students of Guangdong. Environ Pollut Cont [Huan Jing Wu Ran Yu Fang Zhi]. 2010;32:47-50.

55. Yue $Q$, Wang DC, Yu ZQ, Fang RF, Sheng GY, Fu JM. Investigation of polycyclic aromatic hydrocarbons exposure levels in some middle school students in a City in southern China. J Environ Health [Huan Jing Yu Jian Kang Za Zhi]. 2009;26:385-7.

56. Farzan SF, Chen Y, Trachtman H, Trasande L. Urinary polycyclic aromatic hydrocarbons and measures of oxidative stress, inflammation and renal function in adolescents: NHANES 2003-2008. Environ Res. 2016;144:149-57.

57. Pérez-Maldonado IN, Martínez-Salinas R, Pruneda Alvarez LG, Pérez -Vázquez FJ. Urinary 1-hydroxypyrene concentration from Mexican 
children living in the southeastern region in Mexico. Int J Environ Health Res. 2014:24:113-9.

58. Martínez-Salinas Rl, Elena Leal M, Batres-Esquivel LE, Domínguez-Cortinas G, Calderón J, Díaz-Barriga F, et al. Exposure of children to polycyclic aromatic hydrocarbons in Mexico: assessment of multiple sources. Int Arch Occup Environ Health. 2010:83:617-23.

59. Cavanagh JA, Brown L, Trought K, Kingham S, Epton MJ. Elevated concentrations of 1-hydroxypyrene in schoolchildren during winter in Christchurch, New Zealand. Sci Total Environ. 2007;374:51-9.

60. van Wijnen JH, Slob R, Jongmans-Liedekerken G, van de Weerdt RH, Woudenberg F. Exposure to polycyclic aromatic hydrocarbons among Dutch children. Environ Health Perspect. 1996;10:530-4

61. Ma XL, R L, Ding ZH. Analysis of urinary 1-hydroxypyrene of residences in Datong. Adv Environ Sci [Huan Jing Ke Xue Jin Zhan]. 1996;4:60-9.

62. Zhao ZH, Quan WY, Tian DH. Urinary 1-hydroxypyrene level as a biomarker: human exposure to ambient polycyclic aromatic hydrocarbons in China. Ambio. 1995;24:226-30.

63. Ma XL, Ding ZH, Liu RL, Zhao ZH. Polycyclic aromatic hydrocarbons in air and 1-hydroxypyrene in urine from different sampling locations in Datong. Environ Chem [Huan Jing Hua Xue]. 1994;13:536-42.

64. Kanoh T, Fukuda M, Onozuka H, Kinouchi T, Ohnishi Y. Urinary 1 -hydroxypyrene as a marker of exposure to polycyclic aromatic hydrocarbons in environment. Environ Res. 1993;62:230-41.

65. Siwińska E, Mielzyńska D, Smolik E, Bubak A, Kwapuliński J. Evaluation of intraand interindividual variation of urinary 1-hydroxypyrene, a biomarker of exposure to polycyclic aromatic hydrocarbons. Sci Total Environ. 1998;217:175-83.

66. Siwińska E, Mielzyńska D, Bubak A, Smolik E. The effect of coal stoves and environmental tobacco smoke on the level of urinary 1-hydroxypyrene. Mutat Res. 1999:445:147-53.

67. Fiala Z, Vyskocil A, Krajak V, Viau C, Ettlerova E, Bukac J, et al. Environmental exposure of small children to polycyclic aromatic hydrocarbons. Int Arch Occup Environ Health. 2001;74:411-20.

68. Jongeneelen FJ. Benchmark guideline for urinary 1-hydroxypyrene as biomarker of occupational exposure to polycyclic aromatic hydrocarbons. Ann Occup Hyg. 2001;45:3-13.

69. VanRooij JG, Bodelier-Bade MM, Jongeneelen FJ. Estimation of individual dermal and respiratory uptake of polycyclic aromatic hydrocarbons in 12 coke oven workers. Br J Ind Med. 1993;50:623-32.

70. Tjoe Ny E, Heederik D, Kromhout H, Jongeneelen F. The relationship between polycyclic aromatic hydrocarbons in air and in urine of workers in a Söderberg pot room. Am Ind Hyg Assoc J. 1993;54:277-84.

71. Guo Y, Senthilkumar K, Alomirah H, Moon HB, Minh TB, Mohd MA, et al. Concentrations and profiles of urinary polycyclic aromatic hydrocarbon metabolites (OH-PAHs) in several Asian countries. Environ Sci Technol. 2013; 47:2932-8.

72. Zhao ZH, Quan WY, Tian DH. Experiments on the effects of several factors on the 1-hydroxypyrene level in human urine as an indicator of exposure to polycyclic aromatic hydrocarbons. Sci Total Environ. 1992; 113:197-207.

73. Zhang J, Ichiba M, Hara K, Zhang S, Hanaoka T, Pan G, et al. Urinary 1 -hydroxypyrene in coke oven workers relative to exposure, alcohol consumption, and metabolic enzymes. Occup Environ Med. 2001;58:716-21.

74. Yilmazer $M$, Ada AO, Suzen $S$, Demiroglu C, Demirbag AE, Efe $S$, et al. Biological monitoring of environmental exposure to polycyclic aromatic hydrocarbons: 1-hydroxypyrene in urine of Turkish coke oven workers. Bull Environ Contam Toxicol. 2006;76:559-65.

75. Van Rooij JG, Veeger MM, Bodelier-Bade MM, Scheepers PT, Jongeneelen FJ. Smoking and dietary intake of polycyclic aromatic hydrocarbons as sources of interindividual variability in the baseline excretion of 1-hydroxypyrene in urine. Int Arch Occup Environ Health. 1994:66:55-65.

76. Bearer CF. Environmental health hazards: how children are different from adults. Futur Child. 1995;5:11-26.

77. Fan R, Wang D, Mao C, Ou S, Lian Z, Huang S, et al. Preliminary study of children's exposure to PAHs and its association with 8-hydroxy-2'-deoxy guanosine in Guangzhou, China. Environ Int. 2012;42:53-8.
78. Perera F, Viswanathan S, Whyatt R, Tang D, Miller RL, Rauh V. Children's environmental health research - highlights from the Columbia Center for Children's environmental health. Ann N Y Acad Sci. 2006;1076:15-28.

79. Scinicariello F, Buser MC. Urinary polycyclic aromatic hydrocarbons and childhood obesity: NHANES (2001-2006). Environ Health Perspect. 2014; 122:299-303.

\section{Publisher's Note}

Springer Nature remains neutral with regard to jurisdictional claims in published maps and institutional affiliations.

\section{Ready to submit your research? Choose BMC and benefit from:}

- fast, convenient online submission

- thorough peer review by experienced researchers in your field

- rapid publication on acceptance

- support for research data, including large and complex data types

- gold Open Access which fosters wider collaboration and increased citations

- maximum visibility for your research: over $100 \mathrm{M}$ website views per year

At BMC, research is always in progress.

Learn more biomedcentral.com/submissions 